\title{
Myocardial gallium-67 imaging in dilated cardiomyopathy
}

\author{
John B. O'Connell ${ }^{1}$ and Robert E. Henkin ${ }^{2}$ \\ ${ }^{1}$ Section of Cardiology and ${ }^{2}$ Section of Nuclear Medicine, Departments of Medicine and Radiology, Loyola \\ University Medical Center, Maywood, Illinois 60153, USA.
}

\begin{abstract}
Summary: The use of gallium-67, an isotope that is avid for areas of inflammation in patients with dilated cardiomyopathy, is described and compared with endomyocardial biopsy in 68 consecutive patients with dilated cardiomyopathy. Myocarditis was diagnosed in $8 \%$ on biopsy and the likelihood of a positive biopsy when the gallium scan was positive for inflammation, rose to $36 \%$. It is concluded that gallium scanning is a useful adjunct to biopsy in detecting myocarditis in patients with dilated cardiomyopathy and in following patients with evidence of myocarditis on biopsy.

Disadvantages of gallium-67 imaging include the radiation dose accumulated with multiple scans and $72 \mathrm{~h}$ delay from initial injection of the isotope to imaging. It is suggested that definitive conclusions regarding the technique should await the results of a large multicentre trial evaluating gallium in comparison with endomyocardial biopsy in the diagnosis of myocarditis.
\end{abstract}

\section{Introduction}

In some patients with dilated cardiomyopathy (DC), identification of active myocardial inflammation may be of extreme clinical importance because of the disease's poor prognosis (Fuster et al., 1981). Furthermore, there is a recent suggestion that modulation of immune responses by prednisone and azathioprine may induce dramatic clinical improvement (Mason $e t$ al., 1980).

The clinical application of endomyocardial biopsy techniques to DC provides accurate histological diagnosis of myocarditis. Endomyocardial biopsy, although safe in experienced hands, is associated with small but significant morbidity, the increased cost of an invasive procedure and, although specific for the identification of myocarditis, it may lack sensitivity due to the focal nature of the pathological process. Because this technique is furthermore limited to tertiary referral centres, a sensitive and readily available non-invasive technique for screening the large population of patients with DC of recent onset is desirable.

\section{Radioisotopic imaging techniques}

\section{Technetium-99m-pyrophosphate}

Enthusiasm for the use of technetium-99m-pyrophosphate (Tc-99m-PYP) imaging in myocarditis arose from studies in the mouse model of Coxsackie virus B-3

Correspondence: J. B. O’Connell, M.D. myocarditis that lent support to the concept that it may be a valid tool in the screening of patients for myocardial inflammation (Kadota et al., 1979). This interest was magnified by reports that patients with acute myocarditis have Tc-99m-PYP uptake over their myocardium (Mitsutake et al., 1981). Serial histological studies revealed that the intensity of isotopic uptake correlated most closely with evidence of myocyte necrosis yet uptake was decreased when the cellular infiltration was prominent. This observation reinforces prior concepts that this radioisotope is avid for areas of myocardial damage and is not an inflammation-avid isotope (Matsumori et al., 1980). It is, therefore, although a sensitive marker of myocyte damage, not a marker of inflammation and cannot be applied to dilated cardiomyopathy for screening for persistent inflammatory disease.

\section{Gallium-67}

Gallium-67 $\left({ }^{67} \mathrm{Ga}\right)$ was first used in clinical nuclear radiology as a bone scanning agent (Hoffer et al., 1978). Because patients who undergo bone scans may frequently have tumours, the utility of this isotope in imaging soft tissue tumours and lymphomas was readily appreciated and ${ }^{67} \mathrm{Ga}$ is now the standard for staging many malignancies. Since patients with malignancies frequently have inflammatory disease, it was rapidly realized that ${ }^{67} \mathrm{Ga}$ is inflammation-avid. This isotope is now applied in the routine scanning for inflammation with a sensitivity of $90 \%$ but a specificity of only $64 \%$ (Ebright et al., 1982). Acute

(C) The Fellowship of Postgraduate Medicine, 1985 
inflammatory states of the myocardium such as myocardial abscess (Spies et al., 1977) and bacterial endocarditis (Wiseman et al., 1976) have been successfully imaged with this isotope. Gallium-67 imaging has been successfully applied to imaging chronic inflammation in myocardial sarcoidosis (Forman et al., 1983) and pericarditis (O'Connell et al., 1980). In the experimental animal model of isoproterenol-induced myocarditis, gallium-67 uptake proved to be a sensitive technique for identifying active inflammation (Reeves et al., 1981). Chronic inflammatory diseases associated with cell-mediated immune responses such as interstitial pneumonitis (Niden et al., 1976), noninfectious interstitial nephritis (Wood et al., 1978), dermatomyositis (Smith et al., 1979), and rheumatoid arthritis (McCall et al., 1983) can be detected with ${ }^{67} \mathrm{Ga}$. The ${ }^{67} \mathrm{Ga}$ uptake in cell-mediated chronic inflammatory states is dependent on its high avidity for activated lymphocytes (Merz et al., 1974).

Before imaging patients with DC to detect active inflammation, we modified the ${ }^{67} \mathrm{Ga}$ technique (Table I). Conventionally, $5 \mathrm{mCi}$ of gallium-67 citrate is administered intravenously and imaging is performed $72 \mathrm{~h}$ after injection. If imaging is performed at $24 \mathrm{~h}$ in patients with low cardiac output, the ${ }^{67} \mathrm{Ga}$ may not have successfully cleared the blood pool. At $48 \mathrm{~h}$, the background counts remain fairly high decreasing the sensitivity of identification of uptake over the myocardium. Our patients are imaged in the anterior, $45^{\circ}$ and $60^{\circ}$ left anterior oblique, and left lateral projections to 625,000 counts. Most of the liver must be excluded from the field of view since the sensitivity of the technique could be significantly altered by accumulating most of the counts from the dense normal liver uptake. Breast uptake in lactating females will also decrease the sensitivity of detection of myocardial uptake and impair visual identification due to the close proximity of breast tissue to the heart. The patients are imaged on a gamma camera with
Table I Gallium-67 imaging technique

\begin{tabular}{lll}
\hline Dose & - & $5 \mathrm{mCi}{ }^{67} \mathrm{Ga}$ citrate \\
Timing & - & $72 \mathrm{~h}$ post injection \\
Positioning & - & $\begin{array}{l}\text { anterior, } 45^{\circ} \mathrm{LAO}, 60^{\circ} \mathrm{LAO}, \text { left } \\
\text { lateral }- \text { most of liver excluded }\end{array}$ \\
Equipment & - & $\begin{array}{l}\text { gamma camera with medium energy } \\
\text { collimator covering } 93,185, \text { and }\end{array}$ \\
& & $300 \mathrm{keV}$ peaks to 625,000 counts \\
Computer & - & $256 \times 256$ matrix enhanced less than \\
& & $20 \%$
\end{tabular}

medium energy collimation covering the 93,185 and $300 \mathrm{keV}$ peaks of ${ }^{67} \mathrm{Ga}$. The images are then computer processed on a $256 \times 256$ matrix that is enhanced less than $20 \%$ of the maximal pixel.

Subsequent to our initial identification of ${ }^{67} \mathrm{Ga}$ uptake in a small series of patients with DC (Robinson et al., 1979), we systematically scanned 39 patients with idiopathic dilated cardiomyopathy (O'Connell et al., 1981) (Figure 1). Nineteen of these patients had ${ }^{67} \mathrm{Ga}$ uptake over the myocardium. There were no discriminating clinical or haemodynamic features to separate ${ }^{67} \mathrm{Ga}$ positive from negative patients. When 15 of the $19^{67} \mathrm{Ga}$ positive patients were treated with immunosuppression, 6 showed resolution of the uptake within 3 months. These patients uniformly had improvement in functional class and ejection fraction with no mortality. Nine of the patients had persistent myocardial ${ }^{67} \mathrm{Ga}$ uptake and showed no haemodynamic or functional improvement with a 2 year mortality of $67 \%$. These preliminary studies suggested that ${ }^{67} \mathrm{Ga}$ may be avid for the myocardium in some patients with active inflammatory disease but in other individuals uptake appeared unrelated to inflammation, in that uptake persisted despite immunosuppression. These findings prompted a study comparing gallium67 imaging and endomyocardial biopsy in patients
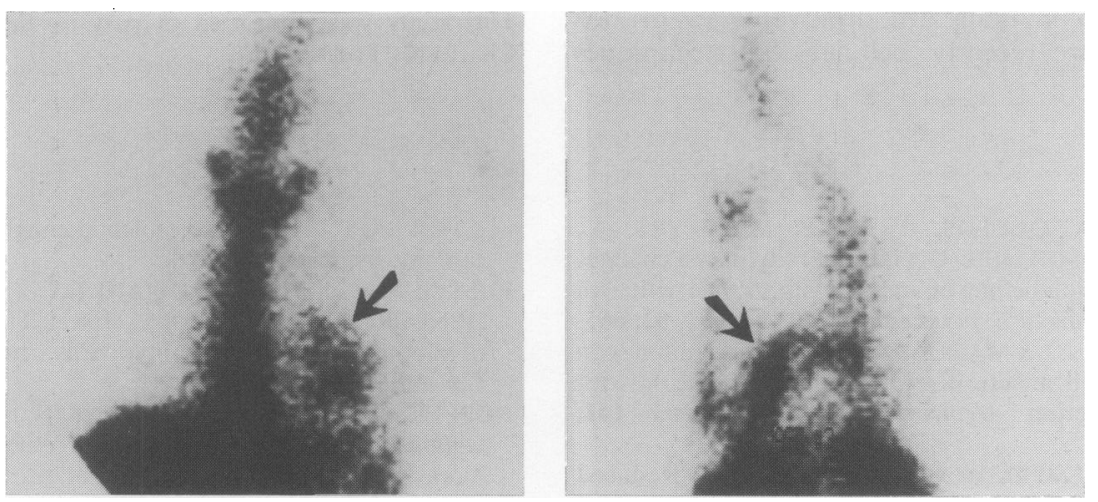

Figure 1 Anterior and $45^{\circ} \mathrm{LAO}$ projections of ${ }^{67} \mathrm{Ga}$ myocardial scan showing uptake over the heart at the arrows. (From Heart Transplant, 2, 13, 1984 - reprinted with permission.) 
with idiopathic dilated cardiomyopathy ( $\mathrm{O}^{\prime}$ Connell $e t$ al., 1984). Seventy-one paired ${ }^{67} \mathrm{Ga}$ myocardial scans and endomyocardial biopsies were performed on 68 consecutive patients. The incidence of myocarditis on biopsy was $8 \%$. The likelihood of a positive biopsy when the ${ }^{67} \mathrm{Ga}$ scan was positive rose to $36 \%$ (Figure 2). Therefore, a positive ${ }^{67} \mathrm{Ga}$ scan improved the yield of endomyocardial biopsy four-fold. Only 1 of 57 negative ${ }^{67} \mathrm{Ga}$ scans had a parallel positive myocardial biopsy. In this individual, there was very dense posterior mediastinal lymph node uptake, perhaps obscuring the ${ }^{67} \mathrm{Ga}$ uptake over the myocardium. Nine patients had a positive gallium scan in the absence of biopsy-proven myocarditis. These patients had an abnormal erythrocyte sedimentation rate $(75 \%$ versus $19 \%$ ) suggesting the possibility that these did not represent false positive ${ }^{67} \mathrm{Ga}$ scans but may, in fact, represent false negative myocardial biopsies due to sampling error. When serial biopsies and gallium scans were performed on patients with biopsy-proven myocarditis, the change in ${ }^{67} \mathrm{Ga}$ uptake paralleled the resolution of inflammatory infiltration. These studies suggest that gallium-67 imaging may be useful in screening patients with dilated cardiomyopathy who have a high yield of myocarditis on biopsy and that gallium-67 imaging is useful in non-invasively following patients with documented myocarditis on biopsy. Gallium-67 uptake in biopsy-proven myocarditis has been confirmed by other investigators (Strain et al., 1983; Shanes et al., 1983). Definitive conclusions, however, await the results of a large multi-centred trial evaluating ${ }^{67} \mathrm{Ga}$ in comparison with endomyocardial biopsy in the diagnosis of myocarditis.

\section{Future prospects}

The technical difficulties associated with gallium- 67 imaging, the radiation dose accumulated with multiple scans, and the $72 \mathrm{~h}$ delay from the initial injection of the isotope to imaging are disadvantages of this technique. More recently, cell labelling techniques

\section{References}

DOLY, A., FINAT-DUCLOS, F., DOLY, M., VEYRE, A., PLAGNE, R. \& MEYNIEL, G. (1983). Study of cell changes induced by radiolabelling of human lymphocytes with $99 \mathrm{~m}$ technetium. Clinical Experiments in Immunology, 52, 665.

EBRIGHT, J., SOIN, J. \& MANOLI, R. (1982). The gallium scan - problems and misuse in examination of patients with suspected infection. Archives of Internal Medicine, 142, 246.

ECKSTEIN, R., MEMPEL, W. \& BOLTE, H.-D. (1982). Reduced suppressor cell activity in congestive cardiomyopathy and myocarditis. Circulation, 65, 1224.

FORMAN, M., SANDLER, M., SACKS, G., KRONENBERG, M.

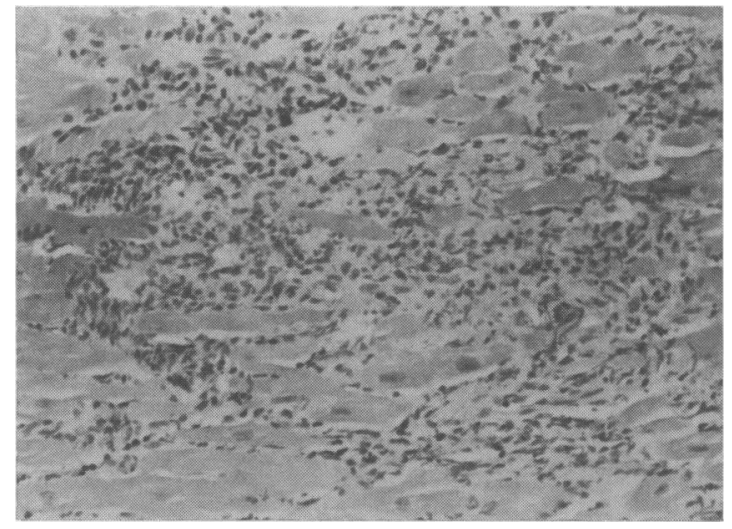

Figure 2 Endomyocardial biopsy from patient whose ${ }^{67} \mathrm{Ga}$ scan is shown in Figure 1 showing a lymphomononuclear cell infiltration with myocyte necrosis compatible with myocarditis. Haematoxylin-eosin original magnification $\times 20$. (From Heart Transplantation, 2, 13, 1984 - reprinted with permission.)

using autologous indium-111-labelled leucocytes or technetium- $99 \mathrm{~m}$-labelled lymphocytes may prove valuable in the evaluation of chronic myocardial disease (Thakur, 1982; Doly et al., 1983). Experimental use of these isotopes in myocardial disease, however, is limited to identifying rejection by indium111-labelled leucocytes and platelets in experimental cardiac transplantation (Wang et al., 1982). It is hoped that clinical studies evaluating the use of these isotopes will be forthcoming so that greater application of radioisotopic techniques to the problem of detection of inflammatory cardiomyopathy subsets may prove practical in the near future.

\section{Acknowledgement}

This study was supported in part by the Earl M. Bane Charitable Trust.

\& POWER, T. (1983). Radionuclide imaging in myocardial sarcoidosis. Chest, 83, 578.

FUSTER, V., GERSH, B.J., GIULIANI, E.R., TAJIK, A.J., BRANDENBURG, R.O. \& FRYE, R.L. (1981). The natural history of idiopathic dilated cardiomyopathy. American Journal of Cardiology, 47, 525.

HOFFER, P., PEKERMAN, C. \& HENKIN, R. (eds) (1978). In Gallium 67 Imaging. p. 1-167. John Wiley and Sons: New York.

KADOTA, K., MATSUMORI, A., KAMBARA, A. \& KAWAI, C. (1979). Myocardial uptake of technetium $99 \mathrm{~m}$ stannous pyrophosphate in experimental viral myopericarditis. 
Journal of Nuclear Medicine, 20, 1047

MASON, J., BILLINGHAM, M. \& RICCI, D. (1980). Treatment of acute inflammatory myocarditis assisted by endomyocardia biopsy. American Journal of Cardiology, 45, 1037.

MATSUMORI, A., KADOTA, K. \& KAWAI, C. (1980). Technetium $99 \mathrm{~m}$ pyrophosphate uptake in experimental viral perimyocarditis. Circulation., 61, 802.

MCCALL, I., SHEPPARD, H., HADDAWAY, M., PARK, W. \& WARD, D. (1983). Gallium 67 scanning in rheumatoid arthritis. British Journal of Radiology, 56, 241.

MERZ, T., MALMUD, L., MCKUSICK, K. \& WAGNER, H. (1974). The mechanism of ${ }^{67} \mathrm{Ga}$ association with lymphocytes. Cancer Research, 34, 2495.

MITSUTAKE, A., NAKAMARA, M., INOU, T., KIKUCHI, Y., TAKESHITA, A. \& FUJINI, S. (1981). Intense persistent myocardial avid technetium $99 \mathrm{~m}$ pyrophosphate scintigraphy in acute perimyocarditis. American Heart Journal, 101, 683.

NIDEN, A., MISHKIN, F. \& KHURANA, M. (1976). 67 Gallium citrate lung scan in interstitial lung disease. Chest, 69, 266.

O'CONNELL, J., ROBINSON, J., HENKIN, R. \& GUNNAR, R. (1980). Gallium 67 citrate scanning for noninvasive detection of inflammation in pericardial diseases. American Journal of Cardiology, 46, 879.

O'CONNELL, J.B., ROBINSON, J.A., HENKIN, R.E. \& GUNNAR, R.M (1981). Immunosuppressive therapy in patients with congestive cardiomyopathy and myocardial uptake of gallium-67. Circulation, 64, 780.

O'CONNELL, J., HENKIN, R.N., ROBINSON, J., SUBRAMANIAN, R., SCANLON, P. \& GUNNAR, G. (1984). Gallium 67 imaging in patients with dilated cardiomyopathy and biopsy proven myocarditis. Circulation, 70, 58.

REEVES, W., JACKSON, G.L., FLICKINGER, F.W., KWEE, H.G., SCHWITER, F.J., WERNER, J., WHITESELL, L. RID-
DLE, M.A., COPENHAVER, G., SHAIKH, B.S. \& ZELIS, R. (1981). Radionuclide imaging of experimental myocarditis. Circulation, 63, 640.

ROBINSON, J., O'CONNELL, J., HENKIN, R. \& GUNNAR, R. (1979). Gallium 67 imaging in cardiomyopathy. Annals of Internal Medicine, 90, 198.

SHANES, J., PAVEL, D., ROBERTSON, A. \& SEYAL, M. (1983). Myocardial gallium 67 imaging and endomyocardial biopsy for the detection of myocarditis (abst). Clinical Research, 31, 711A.

SMITH, W., ROBINSON, R. \& GOBUTY, A. (1979). Positive whole body ${ }^{67} \mathrm{Ga}$ scintigraphy in dermatomyositis. American Journal of Roentgenology, 133, 126.

SPIES, S., MYERS, S., BARRESI, V., GRAIS, M. \& DEBOER, A. (1977). A case of myocardial abscess evaluated by radionuclide techniques: a case report. Journal of Nuclear Medicine, 18, 1089.

STRAIN, J., FINE, E. GROSE, R., KRAMER, D. \& CHO, S. (1983). Factors: comparison of myocardial biopsy and gallium 67 imaging for diagnosing myocarditis (abst). Circulation, 68, III 208.

THAKUR, M. (1982). Cell labelling: achievements, challenges and prospects. Journal of Nuclear Medicine, 22, 1011.

WANG, T., OLUWOLE, S., FAWWAZ, R., WOLFF, M., KUROMOTO, N., SATAKE, K., HARDY, M. \& ALDERSON, P. (1982). Cellular basis for accumulation of In 111 labelled leukocytes and platelets in rejecting cardio allografts. Journal of Nuclear Medicine, 23, 993.

WISEMAN, J., ROULEAU, J., RIGO, P., STRAUSS, H. \& PITT, B. (1976). Gallium 67 myocardial imaging for the detection of bacterial endocarditis. Radiology, 120, 135.

WOOD, B., SHAWA, J., GERMANN, D., WOOD, W. \& CROUCH, T. (1978). Gallium citrate $\mathrm{Ga}^{67}$ imaging in noninfectitious interstitial nephritis. Archives of Internal Medicine, 138, 1665. 